\title{
IDIOPATHIC MYOCARDITIS INVOLVING THE BUNDLE OF HIS
}

\author{
BY
}

\section{TADEUSZ TLUSTY}

From the Central Laboratory and Children's Hospital, Sunderland Hospitals Group

The association of clinical heart block with histological evidence of infiltration of the bundle of His, but without involvement of the ventricular myocardium, in a six-year-old boy is described.

The illness began with generalized abdominal pain and vomiting, accompanied by sore throat and headache. During the first night he had several attacks described as fits. On the second morning his pulse was 60 a minute and he appeared well, but that afternoon was again ill with abdominal pain and a heart rate of 40 a minute. He was admitted to the Children's Hospital, Sunderland.

On initial examination the tongue was slightly furred, the throat inflamed, and the temperature $101^{\circ} \mathrm{F}$. The heart rate was 52 a minute and there was a blowing apical systolic murmur. Slight enlargement of the liver was present. He looked well and no anxiety was felt about his general condition, although the slow pulse rate caused much speculation. Enteric fever was considered and chloromycetin palmitate was given in doses of $250 \mathrm{mg}$. six-hourly. On the third day the lips were cyanosed and the liver was larger: his heart rate was about 40 beats a minute.

Early on the fourth day he collapsed suddenly, with an irregular heart beat about 20 a minute, CheyneStokes respiration, a few basal crepitations, and a large tender liver. He had complete heart block, with partial right bundle-branch block, auricular rate 100, ventricular rate 28 a minute, and notched QRS complexes of $0 \cdot 1 \mathrm{sec}$. duration.

Thereafter he was nursed in an oxygen tent. Atropin was given without affecting the heart rate. He remained critically ill throughout the fourth day; there was constant cyanosis and bradycardia of 20-25 beats a minute. He had several short convulsions and vomited many times. A provisional diagnosis of Fiedler's myocarditis was made. Cortisone, $25 \mathrm{mg}$. six-hourly by intramuscular injection, made no obvious difference. The boy died on the morning of the fifth day.

His previous history contained little significant information. He had been immunized against diphtheria at the age of $2 \frac{1}{2}$ years and had had measles and whooping cough. His parents and three siblings were well.

Throat swab showed neither hæmolytic streptococci nor Corynbacterium diphtheria. Stool culture revealed no pathogens. Blood culture remained sterile. A blood count showed hæmoglobin $10.8 \mathrm{~g}$. per $100 \mathrm{ml}$.; W.B.C., 1600 per cu. mm.; differential count, neotrophils 76 per cent, lymphocytes 19 per cent. and monocytes 5 per cent. Chest X-ray and examination of spinal fluid gave normal results.

Necropsy Findings. The boy was well developed for his age. A few small petechiæ were present on the lower abdomen and over the sternum. Small amounts of fluid were present in all cavities. The lungs, liver, and spleen were congested. The heart was of average size $(110 \mathrm{~g}$.) and showed no gross abnormality. Sterile pus was present in both middle ears. Swabs taken from the throat revealed no pathogens and the pericardial fluid was sterile.

Histology. There were no significant findings in any organ, except the heart, which was infiltrated with neutrophils, lymphocytes, plasma cells, macrophages, and occasional eosinophils (Fig. 1). The parts of the heart involved were the whole of the walls of both atria, including the upper end of the crista terminalis and 
opening of the coronary sinus; a distinct subendocardial band (Fig. 2) corresponding to the anatomical distribution of the left branch of the bundle of His and its ramifications; and a small area in the thickness of the upper third of the septum. No other part of the myocardium and no part of the endocardium was involved.

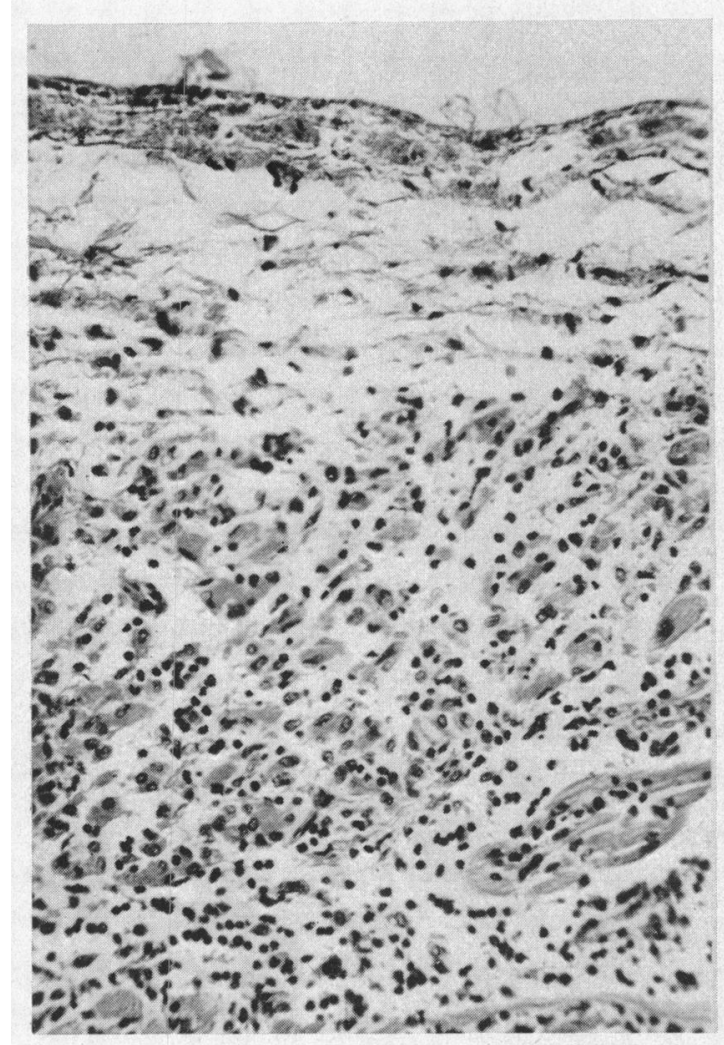

FIG. 1.-Section of interventricular septum, showing subendocardial infiltration. Magnification $\times 260$. Hæmatoxylin-eosin.

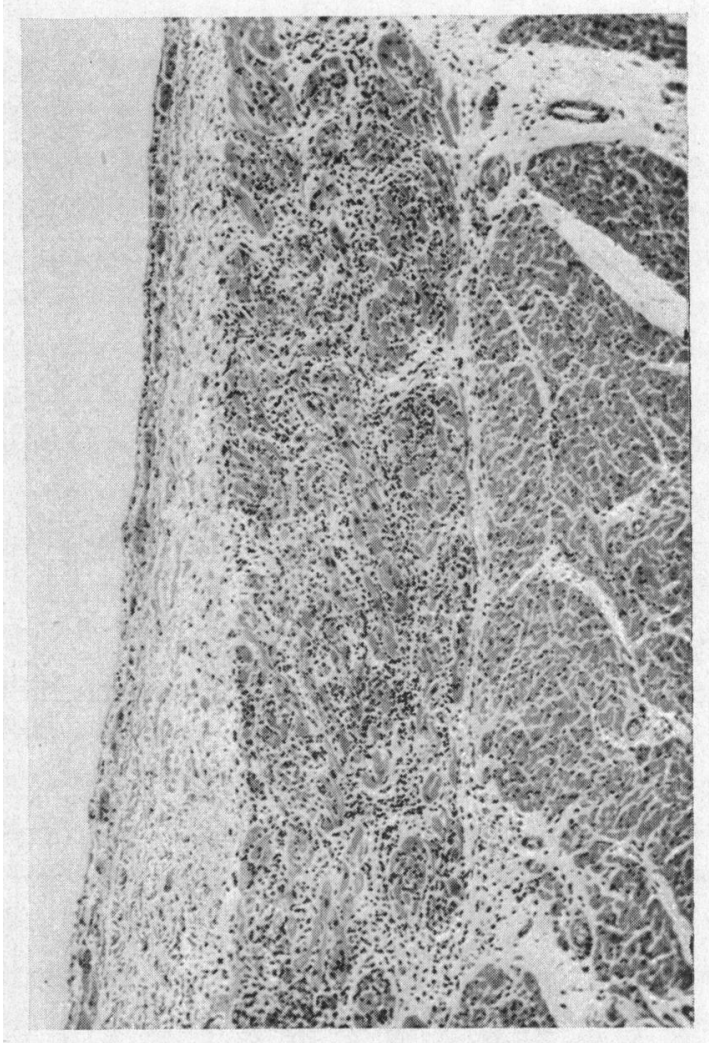

FIG. 2.-Section of interventricular septum. Infiltration of the left branch of the bundle of His. Magnification $\times 80$. Hæmatoxylin-eosin.

The conductive cells of the left bundle branch could be identified most clearly in the middle and lower parts of the septum by morphological characteristics and by a positive staining reaction with periodic acidShiff, which was absent in sections predigested with saliva. When stained with methyl-violet, slight metachromasia was present. Histologically the remainder of the myocardium showed no change and striation was well preserved.

Technique of Tracing Distribution of Infiltration. A block from the interventricular septum showed subendocardial infiltration, in the presumed position of the left branch of the bundle. Sections including both atrial and ventricular wall showed diffuse infiltration of the former with no involvement of the latter. Further blocks were taken to trace the distribution of the infiltration in the septum and ventricular wall; they were numbered, and then marked with small incisions to indicate the anterior and posterior aspects. As each piece of tissue was removed, the gap was filled with a cork block of identical size, marked with a corresponding number. Horizontal paraffin sections stained with $\mathrm{H}$ and $\mathrm{E}$ were examined. On the reverse side of the slide a small piece of adhesive cellophane paper was placed. The outline of the section was traced on this with coloured ink; the infiltration was marked with black ink, using a low-power lens. When dry, the strip of cellophane paper was removed and stuck on to a stiff white card. By this method, the infiltration was visualized at successive levels. The distribution of the infiltration on the left ventricular aspect of the septum was transferred to a life-size photograph of the heart which is reproduced in Fig. 3. 


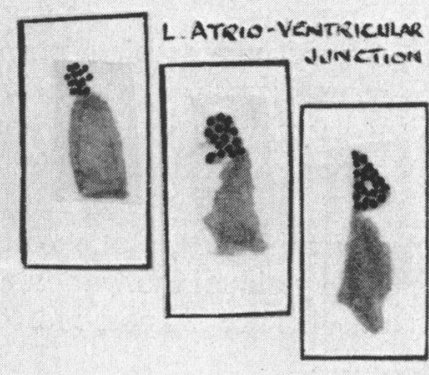

R.ATRIUM AORTA
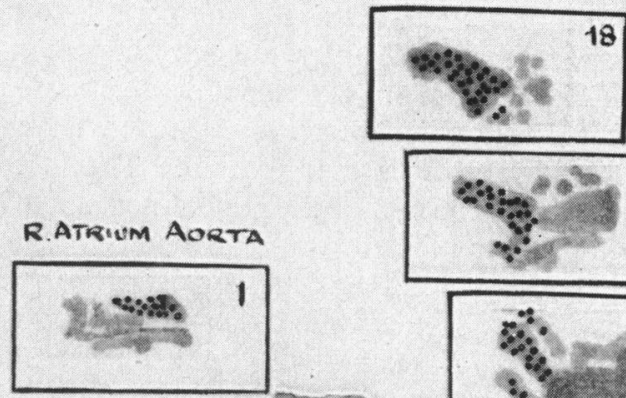

18
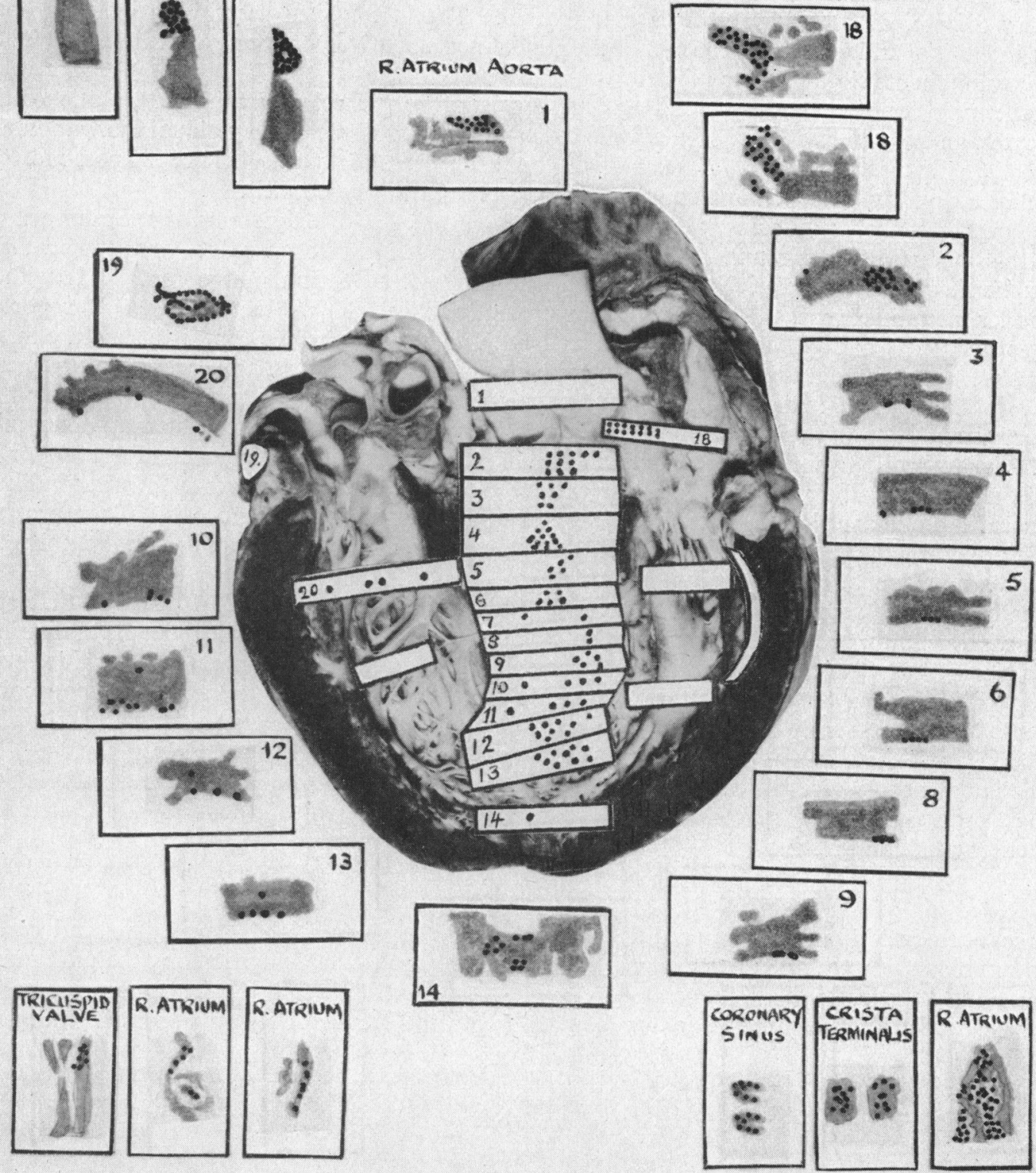

FIG. 3.-At centre, left ventricular aspect of the septum, showing distribution of subendocardial infiltration. The outer diagrams are direct tracings from the microscopical sections showing the areas of infiltration in black (see text).

The sites of the bottom six sections from the right side of the heart, and of those from the left atrio-ventricular junction, are not seen in the photograph.

Blocks without numbers showed no evidence of infiltration. Block 1 shows only infiltration of the right atrial wall, the aortic wall being free. 


\section{Discussion}

Since Fiedler's (1899) original description of idiopathic myocarditis, over 100 similar cases have been reported, often termed primary, isolated, or Fiedler's myocarditis. The distribution is worldwide and all age groups are represented, but young subjects are more commonly affected, with slight male predominance. In Saphir's (1942) classification this variety is grouped under isolated myocarditis. He excludes cases following infectious diseases, rheumatic heart disease, hypertension, coronary disease, or other definable cardiac disease. The histological description includes both diffuse interstitial and granulomatous infiltrations confined exclusively to the myocardium: the other cardiac components should be unaffected.

In the majority of cases the infiltrating cells consist of polymorphs, lymphocytes, plasma cells, monocytes, and/or macrophages. In chronic cases myocardial fibrosis and residual infiltration are described (Williams et al., 1953). Saphir (1942) found 240 cases of myocarditis in 5626 post-mortem examinations and only 15 of these could be defined as isolated myocarditis.

In another series of 97 cases, all children, Saphir et al. (1944) only found three examples of idiopathic myocarditis. Drennan (1953) reported two cases in newborn babies and quoted three others: he discussed the relatively uncommon parenchymatous lesion and compared it with a commoner interstitial type. Amongst the more recent publications Williams et al. (1953) reported 14 cases in infants and children, which included both acute and chronic types: the main clinical features were tachycardia out of proportion to the temperature, cyanosis, and cardiac enlargement.

Several known factors are responsible for a type of lesion similar to that seen in the idiopathic myocarditis. Amongst these are sulphonamide allergy, arsenical intoxication, influenza, pneumonia, diphtheria, and poliomyelitis. Neither the clinical, bacteriological, or histological findings supported any of these as being the responsible agent in the present case. Rheumatic myocarditis was unlikely in view of the clinical picture, absence of Aschoff nodes, and absence of fibrosis. There was no suggestion of syphilitic ætiology, gummata not being present. Parasites and ova were not seen. There was no evidence to suggest avitaminosis.

One case out of fourteen children presented bradycardia (Williams et al., 1953). In that particular case the infiltration was described as patchy, but there were no anatomical details of distribution. Heart block is uncommon in this age group, but has long been recognized in association with congenital ventricular septal defect and has also been described in association with congenital fibrous body neoplasms, cysts, traumatic lesions, and as a result of toxic damage especially following diphtheria. All these conditions, except the last, were excluded by necropsy.

The interest of the present case lies first in the correlation between the clinical and pathological findings, and secondly in the localization of the histological lesion, which is confined to the atria and ventricular conducting tissue.

\section{Summary}

A case of acute idiopathic myocarditis in a six-year-old boy is described. Progressive bradycardia and heart block were the distinctive signs. A simple technique for demonstrating the anatomical distribution of the infiltration is described. Both atria were densely infiltrated. Infiltration below the atrio-ventricular junction appeared to be confined to the bundle of His and its ramifications.

I should like to thank Dr. T. C. Noble for his help with the clinical notes, and Dr. J. F. Wilson for permission to publish this case. To Miss B. D. Stuart I am indebted for secretarial assistance. Mr. W. F. Jones prepared the sections and Mr. J. E. Sinclair took the photographs: I am grateful to them for their painstaking work.

Drennan, J. M. (1953). Arch. Dis. Childh., 28, 288

\section{References}

Fiedler, A. (1899). Festschrift zur Feier des 50 Jarhigen Bestehens des Stadtkrankenhauses zu Dresden-Friedrichsstadt. Dresden.

Saphir, O. (1942). Arch. Path., 33, 88.

, Wile, S. A., and Reingold, I. M. (1944) Amer. J. Dis Child., 64, 294.

Williams, H., O'Reilly, R. N., and Williams, A. (1953). Arch. Dis. Childh., 28, 271. 